\title{
A practical scoring system to predict mortality in patients with perforated peptic ulcer
}

\author{
Ebru Menekse ${ }^{1 *}$, Belma Kocer ${ }^{2}$, Ramazan Topcu ${ }^{3}$, Aydemir Olmez ${ }^{4}$, Mesut Tez ${ }^{1}$ and Cuneyt Kayaalp ${ }^{5}$
}

\begin{abstract}
Introduction: The mortality rate of perforated peptic ulcer is still high particularly for aged patients and all the existing scoring systems to predict mortality are complicated or based on history taking which is not always reliable for elderly patients. This study's aim was to develop an easy and applicable scoring system to predict mortality based on hospital admission data.

Methods: Total 227 patients operated for perforated peptic ulcer in two centers were included. All data that may be potential predictors with respect to hospital mortality were retrospectively analyzed.

Results: The mortality and morbidity rates were $10.1 \%$ and $24.2 \%$, respectively. Multivariated analysis pointed out three parameters corresponding 1 point for each which were age $>65$ years, albumin $\leq 1,5 \mathrm{~g} / \mathrm{dl}$ and BUN $>45 \mathrm{mg} / \mathrm{dl}$. Its prediction rate was high with $0,931(95 \% \mathrm{Cl}, 0,890$ to 0,961) value of AUC. The hospital mortality rates for none, one, two and three positive results were zero, $7.1 \%, 34.4 \%$ and $88.9 \%$, respectively.

Conclusion: Because the new system consists only age and routinely measured two simple laboratory tests (albumin and BUN), its application is easy and prediction power is satisfactory. Verification of this new scoring system is required by large scale multicenter studies.
\end{abstract}

Keywords: Peptic ulcer, Perforation, Mortality, Scoring methods

\section{Introduction}

In treatment of peptic ulcer, incidence of elective surgery tended to decrease due to eradication of Helicobacter pylori during the recent three decades whereas incidence of emergency surgical interventions for complications of the disease did not decrease [1-3]. Moreover, population ageing and extensive use of non-steroid anti-inflammatory drugs increased the incidence of bleeding and perforation of peptic ulcer [1]. Only $5-10 \%$ of the patients with bleeding peptic ulcers require surgical intervention whereas almost all patients with perforated peptic ulcer (PPU) necessitate surgery [1]. The risk of mortality (6-30\%) and morbidity (21-43\%) at PPU unfortunately have not changed during the last decades [1,3-6]. Perforation was the cause of death in $70 \%$ of the patients with peptic ulcer and rate of mortality due to PPU is 10-fold higher than other acute abdominal factors such as acute appendicitis and acute cholecystitis [7].

\footnotetext{
* Correspondence: drebrumenekse@gmail.com

${ }^{1}$ Department of General Surgery, Ankara Numune Training and Research Hospital, Ankara 06100, Turkey

Full list of author information is available at the end of the article
}

Some scoring systems such as Boey, Peptic Ulcer Perforation Score (PULP) and ASA (American Society of Anesthesiologists) have been already developed for prediction of mortality at PPU $[5,8,9]$. PULP score appears to have the greatest predictability of mortality however it is impractical with its complexity [5]. Boey score is a more practical but its predictability value was found varying in several studies [5,10-12]. Both scoring systems require a well history taking to detect the duration of symptoms and co-morbidities [5,8]. However, those data cannot be taken reliably from some elderly patients. ASA as a scoring system is non-specific for PPU, its predictability is not superior than the others and its major drawback is its subjective assessment $[5,10]$. Detection of patients with high risk for mortality after PPU surgery can allow other treatment modalities except surgery or can necessitate some extra care protocols to decrease the mortality [6].

Our aim was to develop a new and easy applicable scoring system to predict mortality at PPU patients.

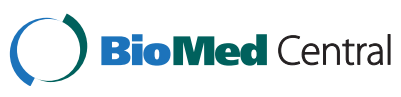

(c) 2015 Menekse et al.; licensee BioMed Central. This is an Open Access article distributed under the terms of the Creative Commons Attribution License (http://creativecommons.org/licenses/by/4.0), which permits unrestricted use, distribution, and reproduction in any medium, provided the original work is properly credited. The Creative Commons Public Domain Dedication waiver (http://creativecommons.org/publicdomain/zero/1.0/) applies to the data made available in this article unless otherwise stated. 


\section{Patients and methods}

The records of surgically treated PPU patients at Ankara Numune Training and Research Hospital and Inonu University Faculty of Medicine between dates 2009 and 2010 were reviewed as retrospectively. The computerized and documentary archives of patients in both of hospital were used in this study. The cases with malignant perforated tumors, marginal ulcer or incomplete data were excluded from the analysis.

The patients were diagnosed according to preoperative clinical features, routine laboratory tests, radiological findings and operative evidence. All the procedures were conducted via an open surgical approach.

The following data were collected: age, gender, white blood cell count (WBC), hemoglobin $(\mathrm{Hb})$, urea, creatinine (Cre), albumin (Alb), systolic blood pressure (BP-S), diastolic blood pressure (BP-D), mean arterial pressure (MAP), pulse, perforation size, admission duration, ASA, Boey, PULP scores, duration of operation, medical illnesses, postoperative complications, reasons of mortality. Laboratory data's were used at the time of admission. The death that occurred within 30 days after surgical treatment or death at the same admission was defined as hospital mortality. The time interval longer than 24 hours between presumed perforation and surgery was accepted as a delayed admission. Factors associated with mortality and morbidity were analyzed using univariate and multivariate analysis. A clinical POMPP (Practical scoring system of mortality in patients with perforated peptic ulcer) score based on the final logistic regression model was constructed for mortality. Additionally, logistic regression analysis and receiver-operating characteristic (ROC) curve analysis were used to calculate risk predictions for mortality in Boey, PULP and ASA scoring systems and their predictability on mortality was compared with the new scoring system. The definitions of the mentioned scoring systems are presented in the Table 1.

Perforation longer than 24 hours was differently defined by PULP and Boey scorings. This term was defined as time interval from perforation (onset of symptoms or aggravation of symptoms) until admission to hospital for PULP [5] whereas this term was defined as the time interval from perforation until surgery for Boey [13]. We also used the definition of Boey scoring system for perforation duration in all scorings. Therefore, total score of PULP may have resulted higher in our study than the original application.

Preoperative shock was defined as blood pressure $<$ $100 \mathrm{~mm} \mathrm{Hg}$ and heart rate $>100$ beats/ min for PULP whereas this term was described as only blood pressure < $100 \mathrm{~mm} \mathrm{Hg}$ for Boey [5,13]. The parameter of preoperative shock was defined compatible with original form of each study in evaluation of these scoring systems in our study.

\section{Statistical analysis}

Shapiro-Wilk test was used for assessing normality. Continuous data are presented as mean \pm SD while differences between groups were analyzed by means of Students $t$ test. Categorical variables were analyzed with $\chi^{2}$ tests. Logistic regression was used to identify variables associated with mortality. Variables with $\mathrm{p} \leq 0.2$ in the univariate analyses were included in multivariate analyses. Results of the multivariable analysis were shown as odds ratio (OR) and

Table 1 Comparison of scoring systems contents for mortality in patients with peptic ulcer perforation

\begin{tabular}{|c|c|c|c|c|c|c|c|c|}
\hline Scoring systems & PULP - points & & ASA - scores & & BOEY - points & & POMPP - points & \\
\hline \multirow[t]{11}{*}{ Substances } & Age $>65$ & 3 & Normal health & 1 & Medical illness & 1 & Age $>65$ & 1 \\
\hline & Comorbid active malign disease or AIDS & 1 & Mild systemic disease & 2 & Preoperative shock & 1 & $\mathrm{BUN}>45 \mathrm{mg} / \mathrm{dl}$ & 1 \\
\hline & Comorbid liver cirrhosis & 2 & Severe systemic disease & 3 & $\begin{array}{l}\text { Duration of peptic } \\
\text { ulcer perforation }>24 \mathrm{~h}\end{array}$ & 1 & Albumin $<1.5 \mathrm{~g} / \mathrm{L}$ & 1 \\
\hline & Concomitant use of steroids & 1 & $\begin{array}{l}\text { Severe systemic disease } \\
\text { with a constant treat to life }\end{array}$ & 4 & & & & \\
\hline & Shock & 1 & $\begin{array}{l}\text { Not expected survival } \\
\text { for patients without surgery }\end{array}$ & 5 & & & & \\
\hline & Perforation time on admission $>24$ & 1 & & & & & & \\
\hline & Serum creatinine $>1.47 \mathrm{mg} / \mathrm{dl}$ & 2 & & & & & & \\
\hline & ASA 2 & 1 & & & & & & \\
\hline & ASA 3 & 3 & & & & & & \\
\hline & ASA 4 & 5 & & & & & & \\
\hline & ASA 5 & 7 & & & & & & \\
\hline High score & & $>6$ & & $>3$ & & $>1$ & & $>1$ \\
\hline Total score & & -18 & & $1-5$ & & $0-3$ & & $0-3$ \\
\hline
\end{tabular}


corresponding 95\% confidence interval (CI). The analysis of the ROC curve used to define the optimal cut-off value for continuous variables in mortality. A clinical score based on the final logistic regression model was constructed; 1 point was given to indicate presence of each predictive factor.

Model discrimination was measured by the area under the receiver-operator characteristic (ROC) curve (AUC). The discrimination of a prognostic model is considered perfect, good, moderate and poor for AUC values of $1 ;>0,8$; $0,6-0,8$ and $<0,6$; respectively.

\section{Results}

We enrolled 325 patients underwent surgical treatment for PPU. A total of 98 patients were excluded because the fulfilled at least one of the exclusion criteria. The study population included remaining 227 patients with a mean age of $50.6 \pm 19.6$ (ranged16-95) years. Table 2 shows the clinical characteristics of PPU patients and comparison of these characteristics for mortality and morbidity according to univariate analysis. Hospital mortality was $10.1 \%$ (n: 23) in the patients while pneumonia, myocardial failure combined with arrhythmia, septicemia and renal failure were found in 15, five, two and one patients, respectively. Morbidity rate was $24.2 \%$ (n: 55 ). The morbidities were pulmonary failure (n:24), wound infection (n:23), evisceration (n:10), renal failure (n:7), postoperative ileus (n:6), cardiac failure $(\mathrm{n}: 5)$, suture leakage $(\mathrm{n}: 3)$ and intraabdominal abscess (n:2)., respectively. Mean length of hospital stay was $7.9 \pm 9.0$ days (ranged 1-115).

The operative procedures included mainly simple closure (n: 218) or some definitive procedures (n:9) such as pyloroplasty or gastrectomy in cases of accompanying hemorrhage, large or multiple perforations.

Three variables were statistically significant in multivariate analysis: albumin level equal or less than 1.5 (OR $=0.0445)$, age over $65(\mathrm{OR}=1.1258)$, and BUN level higher than $45(\mathrm{OR}=1.0353)$ (Table 3$)$. A probability score was calculated by adding points given to these variables. Despite the differences in regression coefficients, 1 point was given for each of these risk factors to simplify procedure. The resulting predicting of mortality in perforated peptic ulcer (POMPP) score ranged between score 0 to 3 .

Table 2 Clinical characteristics of patients in terms of mortality

\begin{tabular}{|c|c|c|c|c|c|c|}
\hline Variable & $\begin{array}{l}\text { Mortality } \\
n=23\end{array}$ & $\begin{array}{l}\text { No Mortality } \\
n=204\end{array}$ & $P$ & $\begin{array}{l}\text { Morbidity } \\
n=55\end{array}$ & $\begin{array}{l}\text { No morbidity } \\
n=172\end{array}$ & $P$ \\
\hline Age (years) (mean $\pm S D)$ & $74.5 \pm 12.1$ & $47.9 \pm 18.4$ & $<0.0001$ & $61.4 \pm 18.1$ & $47.2 \pm 18.8$ & $<0.0001$ \\
\hline Sex; Male/Female $(n, \%)$ & $18(9.1) / 5(15.6)$ & 180(90.9)/27(84.4) & $\mathrm{NS}^{+}$ & $43(21.7) / 12(37.5)$ & $155(78.3) / 20(62.5)$ & 0.047 \\
\hline $\begin{array}{l}\text { White blood cell count }(10 / \mu \mathrm{L}) \\
\text { (mean } \pm \text { SD) }\end{array}$ & $12.5 \pm 7.8$ & $13.7 \pm 6.5$ & $\mathrm{NS}^{+}$ & $146.9 \pm 86.7$ & $132.0 \pm 59.8$ & $\mathrm{NS}^{+}$ \\
\hline Hemoglobin $(\mathrm{g} / \mathrm{dl})($ mean $\pm \mathrm{SD})$ & $12.8 \pm 2.8$ & $15 \pm 2.3$ & $<0.0001$ & $14.3 \pm 3.2$ & $14.9 \pm 2.1$ & $\mathrm{NS}^{+}$ \\
\hline BUN (mg/dl) (mean \pm SD) & $123.5 \pm 85.9$ & $36.6 \pm 20.9$ & $<0.0001$ & $70.5 \pm 67.1$ & $37.4 \pm 26.2$ & $<0.0001$ \\
\hline Creatinine $(\mathrm{mg} / \mathrm{dl})($ mean $\pm \mathrm{SD})$ & $2.71 \pm 2.07$ & $1.15 \pm 0.86$ & $<0.0001$ & $1.78 \pm 1.32$ & $1.20 \pm 1.21$ & 0.003 \\
\hline Albumin $(\mathrm{g} / \mathrm{L})($ mean $\pm \mathrm{SD})$ & $1.52 \pm 0.51$ & $2.57 \pm 0.75$ & $<0.0001$ & $2.45 \pm 0.69$ & $3.12 \pm 0.73$ & $<0.0001$ \\
\hline $\mathrm{BP}_{-} \mathrm{S}^{*}(\mathrm{~mm} / \mathrm{Hg})($ mean $\pm \mathrm{SD})$ & $107 \pm 28.4$ & $125.9 \pm 21.7$ & $<0.0001$ & $124.1 \pm 28.6$ & $123.9 \pm 21.2$ & NSt \\
\hline $\mathrm{BP}-\mathrm{D}^{* *}(\mathrm{~mm} / \mathrm{Hg})($ mean $\pm \mathrm{SD})$ & $67.2 \pm 19.4$ & $76.7 \pm 13.6$ & 0.003 & $77.2 \pm 16.9$ & $75.3 \pm 13.8$ & NSt \\
\hline $\mathrm{MAP}^{* * *}(\mathrm{mmHg})($ mean $\pm \mathrm{SD})$ & $80.4 \pm 21.8$ & $93.1 \pm 15.03$ & $<0.0001$ & $92.8 \pm 19.7$ & $91.5 \pm 14.9$ & NSt \\
\hline Pulse (/ min) (mean \pm SD) & $113.2 \pm 30.2$ & $94.7 \pm 14.3$ & $<0.0001$ & $104.6 \pm 22.3$ & $93.8 \pm 14.7$ & $<0.0001$ \\
\hline \multicolumn{7}{|l|}{$\begin{array}{l}\text { Time from perforation to surgery } \\
\text { (h) }(n, \%)\end{array}$} \\
\hline$<24 \mathrm{~h}$ & $1(1.2)$ & $80(98.8)$ & 0.001 & $28(17.4)$ & $133(82.6)$ & $<0.0001$ \\
\hline$>24 \mathrm{~h}$ & $22(15.1)$ & $124(84.9)$ & & $27(39.7)$ & $41(60.3)$ & \\
\hline \multicolumn{7}{|l|}{ Perforation size $(\mathrm{cm})(\mathrm{n}, \%)$} \\
\hline$<0.5$ & $15(8.9)$ & $153(91.1)$ & 0.02 & $4(13.8)$ & $25(86.2)$ & 0.001 \\
\hline $0.5-1$ & $1(3.4)$ & $28(96.6)$ & & $36(21.1)$ & $135(78.9)$ & \\
\hline$>1$ & $7(23.3)$ & $23(76.7)$ & & $15(50)$ & $15(50)$ & \\
\hline Operation time (min) (mean \pm SD) & $103.3 \pm 42.4$ & $81.6 \pm 28.1$ & 0.001 & $95.7 \pm 46.8$ & $80.3 \pm 22.8$ & 0.002 \\
\hline \multicolumn{7}{|l|}{ Other medical illnesses $(n, \%)$} \\
\hline Absent & $4(2.5)$ & $155(97.5)$ & $<0.0001$ & $22(13.6)$ & $140(86.4)$ & $<0.0001$ \\
\hline Present & $19(27.5)$ & $49(72.1)$ & & $33(48.5)$ & $35(51.5)$ & \\
\hline
\end{tabular}

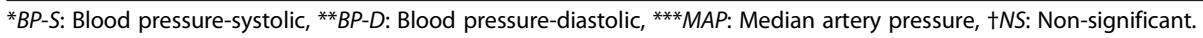


Table 3 Independent predictor of mortality identified by multivariate logistic regression analysis

\begin{tabular}{lllll}
\hline Predictors & $\boldsymbol{P}$ value & $\mathbf{S E}^{*}$ & Odds ratio & $\mathbf{9 5 \%} \mathbf{C l}$ \\
\hline Albumin & 0.0005 & 0.89 & 0.0445 & 0.0077 to 0.2577 \\
BUN & 0.0003 & 0.009 & 1.0353 & 1.0160 to 1.0550 \\
Age & 0.0013 & 0.03 & 1.1258 & $1.0474-1.2100$ \\
\hline
\end{tabular}

*Standard Error.

Three groups of patients were defined based on the POMPP score. In the first group, with a score 0 , there was no mortality. The second group included patients with POMPP score 1 , who had a $7.1 \%$ risk of mortality; this group comprised approximately $1.8 \%$ of the cohort. The third group, comprising approximately $4.8 \%$ of the patients, included those with a POMPP score of 2 whose risk of mortality $34.4 \%$ and last group with a POMPP score of 3 who had an $88.9 \%$ risk of mortality, this group comprised about $3.5 \%$ of the cohort (Table 4 ).

The area under the ROC curve (AUC) was 0.931 (95\% CI, 0.89-0.96) (Figure 1). The AUC values of the other scoring systems evaluated in our study have been presented in Table 5. The specificity, sensitivity, negative likelihood and positive likelihood ratios for POMPP score exceeding 1 point were $89.2 \% ; 82.6 \%$; 0.19 and 7.66 , respectively.

\section{Discussion}

We described a new and easily applicable scoring system to predict the postoperative mortality rate in patients with PPU. This scoring system simply based on only age and routinely measured two simple laboratory tests (albumin, BUN). Similarly to us, PULP or Boey scores were found that age over 65 or 60 was an independent risk factor for mortality $[5,13]$. Advanced age had been reported in several studies as an independent risk factor on mortality in PPU patients [4,14-18] and its importance is still remains $[16,19]$.

Another parameter of POMPP scoring system was BUN level which is regulated as a result of several conditions such as protein catabolism, steroid intake and gastrointestinal bleeding. Regardless of renal functions, it is also accepted as a marker of a severity of disease

Table 4 Risk of mortality according to the POMPP score in patients with peptic ulcer perforation

\begin{tabular}{lll}
\hline POMPP Score & $\begin{array}{l}\text { No Mortality } \\
\mathbf{n}(\%)\end{array}$ & $\begin{array}{l}\text { Mortality } \\
\mathbf{n}(\%)\end{array}$ \\
\hline $\mathbf{0}$ & $130(100)$ & $0(0)$ \\
$\mathbf{1}$ & $52(92.9)$ & $4(7.1)$ \\
$\mathbf{2}$ & $21(65.6)$ & $11(34.4)$ \\
$\mathbf{3}$ & $1(11.1)$ & $8(88.9)$ \\
\hline
\end{tabular}

[20]. In the study of Khuri et al., BUN $>40 \mathrm{mg} / \mathrm{dl}$ was found as a risk factor that increases 30-day mortality after non-cardiac operations [21]. In PULP and Jabolpur scoring systems, high level of serum creatinine was used in predicting risk for mortality [5,12]. In the study of Thorsen et al., serum creatinine level over $1.33 \mathrm{mg} / \mathrm{dl}$ was detected as an independent risk factor that indicates mortality risk in PPU [11]. Additionally, it was stated in this study that hypoalbuminemia and high creatinine levels may reflect some underlying pathologies and diseases such as presence of cancer, chronic severe disease and acute diseases that may cause dehydration or accompany with infection and sepsis [11]. We considered that high predictive power of low albumin and high BUN levels as well as advanced age in mortality is associated with the broad spectrum of underlying pathological events and diseases. Hypoalbuminemia alone had been shown as marker of increased risk of morbidity and mortality in PPU patients [22]. Thorsen et al. was found that hypoalbuminemia was a strong factor which might determine mortality solely (AUC: 0.78) [11]. Strong correlation between hypoalbuminemia and mortality in PPU patients is not surprising when reduction of albumin synthesis is considered in cases of dehydration, hepatic dysfunction, cancer, critical clinical course, systemic inflammatory response syndrome and sepsis [22,23].

PULP scoring system was constructed by testing a large patient population as the national data [5]. Even though, mortality predictive power of PULP scoring system was a little better than ours (PULP AUC: 0,955 vs. POMPP AUC: 9,931; $p>0,5)$, it is not easy to use the PULP in clinical practice. PULP is based on partially anamnesis and admission time was defined as the end of time interval which didn't reflect total duration of abdominal contamination. Additionally, three variables including missing data more than $20 \%$ were excluded from the PULP study and some more missing data below $20 \%$ were included in. Moller et al. was given AUC value of 0.83 for mortality prediction for PULP scoring system [5]. In a recent study by Thorsen et al. found the AUC value as 0.79 [11], whereas we have found it as 0.95 . While calculating the PULP score in our study, we modified the defined time interval as from perforation onset to the surgery. For this reason, prediction of PULP in our analysis might be higher than the previously reported ones.

The other defined scoring system of Boey is more practical than the PULP. However, prediction values of Boey scoring system were quite varying in several studies as AUC values ranged between 0,63 to $0,86[5,11,12,15,24]$. In our analysis we found a better Boey value (AUC: 0.92) for prediction then the reported ones. On the other hand, Boey scoring system didn't involve advanced age which is generally an important parameter for mortality in PPU [8]. 


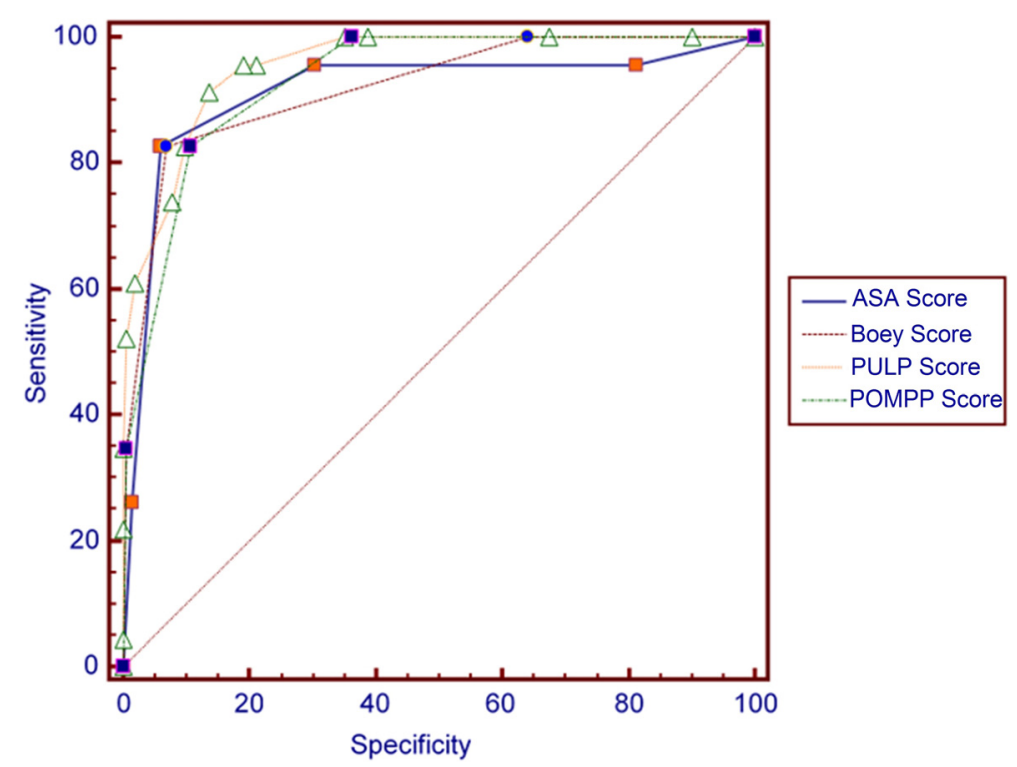

Figure 1 ROC curves analysis of POMPP, PULP, Boey and ASA scoring system.

Exclusion of advanced age might be caused by the fact that this scoring system was defined three decades before. Incidence of PPU complications increased in the population of advanced age due to prolonging mean lifetime in the present time and increased use of NSAIs in the advanced ages [25].

Several studies were analyzed the mortality prediction of ASA status in PPU patients and found AUC values between 0,73 and $0,91[5,9,11,15]$. ASA is not specific scoring system for neither PPU and it is mainly based on the co-morbid diseases and their severity $[11,25,26]$. Although co-morbidities are important risk factors for mortality, under diagnosed or unknown chronic diseases on emergency admission can result to underscoring of ASA. On the other hand, sepsis is as important as the additional medical diseases on the mortality of PPU $[4,6,9]$. Beside all that, the main problem of ASA scoring is that calculation is performed subjectively and differences between interpretations may be observed [10].

In fact, all of the scoring system models compared in our study had similar and well predictive power for

Table 5 The ROC curves results of different scoring system for mortality in peptic ulcer perforation

\begin{tabular}{llll}
\hline Scoring Systems & AUC & SE $^{*}$ & $\mathbf{9 5 \%} \mathbf{C l}$ \\
\hline ASA & 0.914 & 0.0401 & 0.870 to 0.947 \\
BOEY & 0.920 & 0.0282 & 0.876 to 0.952 \\
PULP & 0.955 & 0.0164 & 0.919 to 0.978 \\
POMPP & 0.931 & 0.0195 & 0.890 to 0.961 \\
\hline
\end{tabular}

*Standard Error. mortality in PPU patients. None of the previously described scoring systems were widely accepted in clinical practice yet. The reason can be their complexity, non-specificity or confused and subjective points in the mind of clinicians such as definitions of preoperative shock, perforation duration and severity of medical illnesses. We believe that three very clear parameters (age, albumin and BUN) can be easily adopted in the clinical practice to predict the surgical mortality of PPU patients. Respiratory support, circulatory stabilization, preoperative and postoperative care in ICU, frequent monitorization and perioperative care protocols can be added to the high risk patients with PPU $[5,6]$. It is demonstrated that if the high risk patients got extra perioperative care, the hospital mortality rate could be reduced from the standard care patients $(17 \%$ and $27 \%$, respectively, $p=$ 0.005) [6]. Therefore, a simple and easy applicable system in predicting mortality for PPU patients may provide reduction in mortality rates.

As a limitation, our study population was only 227 but this number was noticeable when compared with other studies in the literature except cohort study of Moller $[5,11,13,15]$. Secondly, this was a retrospective analysis, and its prospective confirmation is evitable.

\section{Conclusion}

POMPP is a very simple and appropriate scoring system for clinical practice that may allow surgeon to perform a rapid analysis and may help in predicting mortality rate in PPU with its construction based on objective data. 


\section{Competing interests}

The authors declare that they have no competing interests.

\section{Authors' contributions}

Study conception or design: EM, BK. Data collection: AO, RT. Statistical analysis: MT, BK, EM, interpretation: EM, drafting or revision of the manuscript: BK, CK, MT, EM and critical reviewed and approval: EM, BK, RT, AO, MT, CK. All authors read and approved the final manuscript.

\section{Author details}

${ }^{1}$ Department of General Surgery, Ankara Numune Training and Research Hospital, Ankara 06100, Turkey. ${ }^{2}$ Department of General Surgery, Faculty of Medicine, Sakarya University, Sakarya 54000, Turkey. ${ }^{3}$ General Surgery Clinic, Turhal State Hospital, 60300 Tokat, Turkey. ${ }^{4}$ Department of Surgery, Faculty of Medicine, Mersin University, 33343 Mersin, Turkey. ${ }^{5}$ Department of Surgery, Faculty of Medicine, Inonu University, 44280 Malatya, Turkey.

Received: 12 January 2015 Accepted: 16 February 2015

Published online: 21 February 2015

\section{References}

1. Lee CW, Sarosi Jr GA. Emergency ulcer surgery. Surg Clin North Am. 2011;91:1001-13. doi:10.1016/j.suc.2011.06.008.

2. Sarosi Jr GA, Jaiswal KR, Nwariaku FE, Asolati M, Fleming JB, Anthony T. Surgical therapy of peptic ulcers in the 21st century: more common than you think. Am J Surg. 2005;190:775-9.

3. Lau JY, Sung J, Hill C, Henderson C, Howden CW, Metz DC. Systematic review of the epidemiology of complicated peptic ulcer disease: incidence, recurrence, risk factors and mortality. Digestion. 2011;84:102-13. doi:10.1159/000323958.

4. Kim JM, Jeong SH, Lee YJ, Park ST, Choi SK, Hong SC, et al. Analysis of risk factors for postoperative morbidity in perforated peptic ulcer. J Gastric Cancer. 2012;12:26-35. doi:10.5230/jgc.2012.12.1.26.

5. Møller MH, Engebjerg MC, Adamsen S, Bendix J, Thomsen RW. The Peptic Ulcer Perforation (PULP) score: a predictor of mortality following peptic ulcer perforation. A cohort study. Acta Anaesthesiol Scand. 2012;56:655-62. doi:10.1111/j.1399-6576.2011.02609.x.

6. Møller MH, Adamsen S, Thomsen RW, Møller AM. Peptic Ulcer Perforation (PULP) trial group. Multicentre trial of a perioperative protocol to reduce mortality in patients with peptic ulcer perforation. Br J Surg. 2011;98:802-10. doi:10.1002/bjs.7429.

7. Søreide K, Thorsen K, Søreide JA. Strategies to improve the outcome of emergency surgery for perforated peptic ulcer. Br J Surg. 2014;101:e51-64. doi:10.1002/bjs.9368.

8. Boey J, Choi SK, Poon A, Alagaratnam TT. Risk stratification in perforated duodenal ulcers. A prospective validation of predictive factors. Ann Surg. 1987:205:22-6.

9. Mäkelä JT, Kiviniemi H, Ohtonen P, Laitinen SO. Factors that predict morbidity and mortality in patients with perforated peptic ulcers. Eur J Surg. 2002;168:446-51.

10. Thorsen K, Søreide JA, Søreide K. Scoring systems for outcome prediction in patients with perforated peptic ulcer. Scand J Trauma Resusc Emerg Med. 2013;21:25. doi:10.1186/1757-7241-21-25.

11. Thorsen K, Søreide JA, Søreide K. What is the best predictor of mortality in perforated peptic ulcer disease? A population-based, multivariable regression analysis including three clinical scoring systems. J Gastrointest Surg. 2014;18:1261-8. doi:10.1007/s11605-014-2485-5.

12. Mishra A, Sharma D, Raina VK. A simplified prognostic scoring system for peptic ulcer perforation in developing countries. Indian J Gastroenterol. 2003:22:49-53.

13. Boey J, Wong J, Ong GB. A prospective study of operative risk factors in perforated duodenal ulcers. Ann Surg. 1982;195:265-9.

14. Kocer B, Surmeli S, Solak C, Unal B, Bozkurt B, Yildirim O, et al. Factors affecting mortality and morbidity in patients with peptic ulcer perforation. J Gastroenterol Hepatol. 2007;22:565-70.

15. Lohsiriwat V, Prapasrivorakul S, Lohsiriwat D. Perforated peptic ulcer: clinical presentation, surgical outcomes, and the accuracy of the Boey scoring system in predicting postoperative morbidity and mortality. World J Surg. 2009;33:80-5. doi:10.1007/s00268-008-9796-1.
16. Thorsen K, Søreide JA, Kvaløy JT, Glomsaker T, Søreide K. Epidemiology of perforated peptic ulcer: age- and gender-adjusted analysis of incidence and mortality. World J Gastroenterol. 2013;19:347-54. doi:10.3748/wjg.v19.i3.347.

17. Kujath P, Schwandner O, Bruch HP. Morbidity and mortality of perforated peptic gastroduodenal ulcer following emergency surgery. Langenbecks Arch Surg. 2002;387:298-302

18. Hermansson M, Staël Von Holstein C, Zilling T. Peptic ulcer perforation before and after the introduction of $\mathrm{H} 2$-receptor blockers and proton pump inhibitors. Scand J Gastroenterol. 1997;32:523-9.

19. Di Saverio S, Bassi M, Smerieri N, Masetti M, Ferrara F, Fabbri C, et al. Diagnosis and treatment of perforated or bleeding peptic ulcers: 2013 WSES position paper. World J Emerg Surg. 2014;9:45. doi:10.1186/1749-7922-9-45.

20. Uchino S, Bellomo R, Goldsmith D. The meaning of the blood urea nitrogen/creatinine ratio in acute kidney injury. Clin Kidney J. 2012;5:187-91. doi:10.1093/ckj/sfs013.

21. Khuri SF, Daley J, Henderson W, Hur K, Demakis J, Aust JB, et al. The Department of Veterans Affairs' NSQIP: the first national, validated, outcome-based, risk-adjusted, and peer-controlled program for the measurement and enhancement of the quality of surgical care. National VA Surgical Quality Improvement Program. Ann Surg. 1998;228:491-507.

22. Møller MH, Adamsen S, Thomsen RW, Møller AM. Preoperative prognostic factors for mortality in peptic ulcer perforation: a systematic review. Scand J Gastroenterol. 2010;45:785-805. doi:10.3109/00365521003783320.

23. Ñamendys-Silva SA, González-Herrera MO, Texcocano-Becerra J, Herrera-Gómez A. Hypoalbuminemia in critically ill patients with cancer: incidence and mortality. Am J Hosp Palliat Care. 2011;28:253-7. doi:10.1177/1049909110384841.

24. Buck DL, Vester-Andersen M, Møller MH. Accuracy of clinical prediction rules in peptic ulcer perforation: an observational study. Scand J Gastroenterol. 2012;47:28-35. doi:10.3109/00365521.2011.639078.

25. Owens WD. American Society of Anesthesiologists Physical Status Classification System in not a risk classification system. Anesthesiology. 2001;94:378

26. Daabiss M. American Society of Anaesthesiologists physical status classification. Indian J Anaesth. 2011;55:111-5. doi:10.4103/0019-5049.79879.

\section{Submit your next manuscript to BioMed Central and take full advantage of:}

- Convenient online submission

- Thorough peer review

- No space constraints or color figure charges

- Immediate publication on acceptance

- Inclusion in PubMed, CAS, Scopus and Google Scholar

- Research which is freely available for redistribution 